\title{
Consumer innovation resistance as routines: is it an obstacle to development and well-being?
}

\author{
Marina Ryzhkova ${ }^{1, a}$, Artem Dibrov ${ }^{1}$, and Alexandra Shchukina ${ }^{1}$ \\ ${ }^{1}$ National Research Tomsk Polytechnic University, Department of Economics, Lenin Avenue, 30, 634050, Tomsk, Russia
}

\begin{abstract}
In this article we define the role of innovation in the economy of knowledge and in providing social and economic wellbeing to the population. The innovation resistance is defined as a complex phenomenon and as a result of agent-object relationships. Then the article is focused on consumer innovation resistance as a main obstacle to development of knowledge-based economy. Two types of consumer innovation resistance are revealed. The source of active consumer innovation resistance is the result of non-compliance of consumer expectations and characteristics of a new product. Passive consumer innovation resistance comes from the lack of desire to change stable behavior patterns and from unwillingness to learn. Also we classify the deterministic factors of consumer innovation resistance as exogenous indirect and direct factors and as endogenous factors, what can help to work out a general approach to overcoming the innovation resistance. Innovations can be considered as habits and routines to changes, which can be developed and distributed both to the young population and to the elderly. Some insights in this direction are offered.
\end{abstract}

\section{Introduction}

Innovation activity as an indicator of development of the knowledge economy and information society is one of the key indicators of well-being. The close interaction between the innovation processes and well-being can be explained by the following facts:

1. Innovations improve labour efficiency and competitiveness.

2. Innovations foster economic diversity.

3. Innovations are focused on improvement of living standards, which is revealed in social indicators.

The knowledge economy is the modern stage of economic development. It is intended to improve the quality of human capital and implement high-tech knowledge and services. The knowledge economy involves a special type of society where innovations are widely implemented in economic, social and cultural spheres. So it boosts individual social and economic well-being. The economic well-being is individual's satisfaction with living conditions. Social well-being is the measurement of contingency between the individual and society and is crucial in determining the life quality for elderly especially when an economy is subjected to structural changes. For this reason there is a problem of old people adaptation to certain specific social and economic conditions in the transformation-to-theknowledge-economy period.
We are of the opinion that the main obstacle on the way to knowledge economy and social well-being is innovation resistance. The innovation resistance slows down the process of creation, diffusion and application of innovations. Innovation resistance can occur on the side of any stakeholder in the innovation process. It may be revealed at the level of organization or as an interaction between market agents in the process of diffusion of innovation.

This article emphasizes the innovation resistance in the process of innovation diffusion. It means that innovation resistance stems from consumers of innovations. The most interesting processes take place in the elderly group.

\section{Innovation resistance as a category}

Innovation resistance is a systematic phenomenon which is characterized by a degree of integrity to some extent [1]. It means that this phenomenon includes not only individual actions but also relations between individuals within an organization who are in opposition to a particular innovation.

It is important to distinguish the agent and the object of innovation resistance in order to:

- specify the causes of innovation resistance;

- reveal specific features of changes;

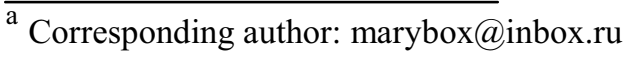


- identify the problem of innovation in regard to market agents.

There are some definitions of innovation resistance in terms of agent-object relations [2, 3, 4, 5]; let us summarize them in Table 1.

Table 1. Definitions of innovation resistance

\begin{tabular}{|c|c|c|c|}
\hline $\begin{array}{c}\text { Environ- } \\
\text { ment }\end{array}$ & $\begin{array}{l}\text { Approaches to } \\
\text { innovation } \\
\text { resistance }\end{array}$ & Agents & Objects \\
\hline Internal & $\begin{array}{l}\text { * mental set or } \\
\text { behaviour which } \\
\text { demonstrates the } \\
\text { unwillingness to } \\
\text { drive changes } \\
\text { * behaviour of } \\
\text { organization's } \\
\text { members aimed } \\
\text { at disrupting and } \\
\text { discrediting } \\
\text { structural } \\
\text { reforms. } \\
\text { * a set of } \\
\text { contradictions } \\
\text { which takes place } \\
\text { in the process of } \\
\text { interaction } \\
\text { between } \\
\text { innovation and an } \\
\text { organization }\end{array}$ & $\begin{array}{l}\text { individual, } \\
\text { organization's } \\
\text { members }\end{array}$ & $\begin{array}{l}\text { organizational } \\
\text { changes, } \\
\text { structural } \\
\text { transformation } \\
\text { of an } \\
\text { organization }\end{array}$ \\
\hline External & $\begin{array}{l}\text { * total or partial } \\
\text { market agents' } \\
\text { (consumers') } \\
\text { refusal to } \\
\text { transact business } \\
\text { with one or more } \\
\text { external market } \\
\text { agents } \\
\text { * consumer } \\
\text { boycott in } \\
\text { response to } \\
\text { emergence of an } \\
\text { innovation } \\
\text { * negative } \\
\text { consumer } \\
\text { attitudes } \\
\text { innovation due to } \\
\text { high transaction } \\
\text { costs } \\
\text { * long-term } \\
\text { consumer } \\
\text { postponement in } \\
\text { innovation trial } \\
\text { * consumer } \\
\text { resistance to } \\
\text { change in order to } \\
\text { keep their status } \\
\text { quo or values }\end{array}$ & $\begin{array}{l}\text { consumer, } \\
\text { consumer } \\
\text { group, firms }\end{array}$ & $\begin{array}{c}\text { market agents, } \\
\text { new } \\
\text { technologies, } \\
\text { product } \\
\text { innovations }\end{array}$ \\
\hline
\end{tabular}

It is important to note that innovation resistance is a steady state. The reason is that it tends to selfpreservation due to institutional inertia of society. The institutional inertia slows down the process of social modernization and makes it difficult for knowledge economy to appear. So innovation changes are linked to social and cultural characteristics (values, social norms and roles). It means that an economic system can be ready to changes if consumers are ready to innovations. In that way an economic system can show a growth of innovation activity and improve social and economic well-being. Therefore, an application of innovation can be successful if it succeeds in overcoming innovation resistance of organizations and consumers.

Modern scientific views on the commercialization of innovations can be represented by the following triad: innovation, consumer, promotion. However, in practice each separate part of the triad cannot secure the achievement of good economic results but it is the source of market failures of high-tech products and technologies. It is worth noting that if there is exhaustive information on the characteristics of an innovative commodity, it does not presume that an innovation will be adopted by the market. The origin of innovation failure is in the innovation resistance of organizational and consumer environments.

Consumer innovation resistance is an unexpected subjective reaction of a consumer community to the emergence of new customer appeal of the products. The response can take a form of passive or active consumer innovation resistance. Passive consumer innovation resistance occurs before the trial of new products due to the consumer's genetic propensity to reject innovations or new knowledge. In addition, passive consumer innovation resistance can be a result of information overload or low awareness of potential consumers about functionality and performance of a new product. Useless information about a new product can cause an annoyed consumer response and lead to rejection of purchasing a new product. Consumers can be unmotivated to know more about new products because of ingrained consumer habits and routines. Active consumer innovation resistance may appear after even one trial of a new product. This type of innovation resistance is the result of contradiction between consumer's expectations and consumer's impression after trial. Consumers can show knowledgeable behavior and reject an innovation because of its functional or institutional characteristics; the latter include values, social norms, and patterns of consumer behavior. Thus, consumer innovation resistance is determined by many factors, such as consumer expectations, attitudes, and impressions of the process from the personal point of view and of an institutional reality of consumer market from the social viewpoint of the process.

It is clear that innovations should be sustainable in case of a multidimensional system of consumer preferences in order to overcome consumer innovation resistance and improve social and economic well-being. In order to succeed, innovations have to be accessible and understandable for all categories of consumers of all ages. The age factor has an effect on the consumer level of innovation resistance. But it is critical to underscore that some younger people are more resistant to change than older ones [6]. It occurs due to the accumulation of negative consumer experience during the lifetime. 
There is the system of determining factors of consumer innovation resistance, shown in Figure 1.

\begin{tabular}{|c|c|c|}
\hline \multirow{7}{*}{ 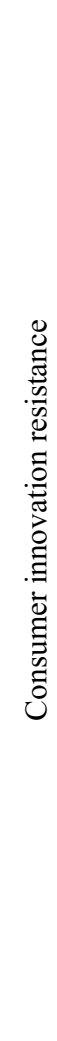 } & \multicolumn{2}{|c|}{ Indirect exogenous factors } \\
\hline & \multicolumn{2}{|c|}{$\begin{array}{c}\text { Political factors } \\
\text { Legal factors } \\
\text { Development of market relations } \\
\text { Types of technological structures } \\
\text { Types of culture } \\
\text { Phase of the business cycle } \\
\end{array}$} \\
\hline & \multicolumn{2}{|c|}{ Direct exogenous factors } \\
\hline & Innovation producer & Social groups \\
\hline & $\begin{array}{l}\text { Price policy } \\
\text { Product policy (consumer } \\
\text { properties of a new product, } \\
\text { complexity of a trial, } \\
\text { ergonomic aspects of } \\
\text { innovation) } \\
\text { The quality of conformance } \\
\text { between innovations and the } \\
\text { system of cultural norms } \\
\text { Communication policy } \\
\text { (advertising, sale promotion, } \\
\text { public relations) }\end{array}$ & $\begin{array}{l}\text { Impact of reference } \\
\text { groups on personal } \\
\text { values (family, } \\
\text { work collective, } \\
\text { group of young or } \\
\text { older people) } \\
\text { Rumors about } \\
\text { consumer } \\
\text { propensity } \\
\text { concerning new } \\
\text { products. }\end{array}$ \\
\hline & \multicolumn{2}{|c|}{ Endogenous factors } \\
\hline & \multicolumn{2}{|c|}{$\begin{array}{l}\text { Consumer cognitive perception of innovations } \\
\text { Consumer's status quo } \\
\text { Genetic propensity for changes } \\
\text { Patterns of consumer behavior } \\
\text { Personal values and motives }\end{array}$} \\
\hline
\end{tabular}

Fig. 1. Determining factors of consumer innovation resistance

According to Figure 1, the indirect exogenous factors have a direct impact on innovation producers (firms) and consumers. The innovation producers elaborate on parameters, price, product and communication policy, taking into account the effects of indirect exogenous factors. The consumer response to the impact of an innovation producer has specific forms and can result in purchase of the new product. Thus, innovation producer should not forget about specifics of consumer demand and about cumulative impact on innovation of exogenous and endogenous factors.

\section{Routinization and Consumer Innovation Resistance}

A revolutionary book "The Evolutionary Theory of Economic Change," written by W. Nelson and S. Winter in 1982 introduced into scientific use the term "routine", focusing on its role in economy and in institutional economic theory. Routine as a basic point or a central unit of analysis can describe the process of decision making of individuals or organizations. In 1964, S. Winter defined routine as "a pattern of behaviour that is repeated regularly, but is subjected to change if conditions change" [7]. Routines are patterns of behaviour, which are composed of four components: "action", "activity", "behaviour" and "interaction". Typically, the action and activity are used interchangeably in the literature, but there is a difference between "action" and "behaviour". The latter implies observability and a response to stimuli. The component "interaction" is likely to be the characteristic of organizational routines as it involves a number of actors, and organizational routines differ from individual ones. Routines as the actions imply the difference between unconscious processes (cognitive regularities) and samples of thinking (cognitive patterns).

Routines are an essential feature of any human behaviour; it explains the mechanism of many of the most common and universally accepted theoretical concepts. While routine is recognized as an essential aspect of saving cognitive efforts of a consumer, it is also a source of inertia, immobility, and even unconsciousness in the actions of people. In this sense, routine resists a change.

The fact is that human behavior does not function without templates. And, in order to introduce changes, some special routine is required as well. It is sometimes called "meta-routine", which means a routine intended for changing other routines [8]. These routines are templates for the acquisition of new information, thus adapting to new, unfamiliar conditions, as well as the ability to modify these templates. But not only this. Most of the existing routines have an innovative component that allows changing the routine from within. Let us expand on this idea.

Routine is dualistic, which is revealed in two aspects: the implicit aspect and the behavioral aspect. The explicit aspect represents an ideal or a schematic form of routines. This is an abstract or general idea of routine or routine in principle. The behavioral aspect includes specific actions taken by specific people at a specific time and in a particular place; it is routine in practice. The combination of the two aspects activates the routine, makes/keeps it working.

Even if the explicit aspect of the routine is planned step-by-step, and there are clear instructions on what actions to take, every time a person not only re-designs the routine, but also reflects on his/her actions. Even on the assembly line workers tend to diversify their movements, not to mention less strict routines. It is inherent in human nature to modify one's behavior in order to diversify (involuntary change), as well as to reflect on the effectiveness of one's actions, so that the routine is subjected to intentional change. Or, in other words, consumers interpret their actions to make sense of what they do. And even if sometimes their actions seem to be automatic or unconscious, a person always has the opportunity to confront the expectations and act differently. It is the basis for changes.

The existence of stable behavior patterns and routines leads to resistance to innovation changes at the level of an individual or a group. Individual active or passive innovation resistance is determined by psychological unwillingness to recognize the objectivity of external changes and to adopt organizational or consumer innovations. Employees with similar views on the problems of changes are usually gather in groups with the homogeneous organizational cultural framework. Therefore, conservative groups of consumers or organization's members are sources of active or passive 
innovation resistance. It is important to emphasize that the application of innovations means adoption of new routines. In this context, innovation resistance is a result of conflict between current and new routines.

\section{Routinisation in the older age group}

In case of young consumers, the situation is relatively simple: they tend to learn new routines very quickly thus imitating or acquiring routines of a new type. With more mature people, who are accustomed to a certain routine and rhythm of life, the process is more complicated. The modern world is changing extremely rapidly in terms of information, daily routines and skills for their adoption. Such situation necessitates upgrading the skills of older people. This is especially true regarding technical innovations. A small percentage of the elderly becomes early adopters of new products; they would rather join at later stages of the product life cycle [9].

Among the older age group (65+) using the internet technology, the crucial factors of acquisition of new skills are curiosity and active desire to understand the principle of work, which leads to the development of stable routines and to an increase in the frequency of internet connections. Moreover, the elderly not only begin to use the technology on their own, but also actively teach their elderly friends [10].

The researchers reveal the connection between the use of computers, modern technologies and the age: the younger the consumer is, the easier is the process of adaptation. The obstacles for computer use are price of the equipment, psychological fears and experience in use of other technologies [11].

Old people also begin to engage in the 'Social networking websites' (SNW) use [12]. The main factors that influence the adoption of the internet networks are perceived usefulness, trust in SNW, and frequency of Internet connections. Perceived usefulness means that a user believes that some technology will help him/her to achieve a certain goal. Perceived ease of use only makes the process more comfortable, but has no encouraging effect. Trust in technology is crucial for SNW because these computer-mediated communications are personal and require protection of user's privacy. Sometimes trust is even a better predictor, for example, for online shopping than familiarity with technologies [13]. The age itself does not play such an important role in the Internet use. It is rather perceived as a declining physical condition (or analog usage or frequency of use of the same systems) $[14,15]$.

Online shopping is not very popular among old people because older consumers are less likely to share «wired lifestyle» [16] Frolova that means they do not always connect to the internet and, thus, less likely to share the belief that the internet shopping saves them money and that the internet recommendations are trustworthy [17].

According to the research, new technologies should be adjusted to the elderly users [18]. Firstly, the elderly quite rarely use advanced technological functions. Secondly, they prefer physical keyboards to enter texts, even when they use on-screen keyboards, they prefer tapping the touch pad. Thirdly, elderly people have difficulties in mental representation of the mobile phone menus. Finally, the phone should be big but comfortable to hold, with a contrasting colour scheme.

At the same time in a situation of modern demographic trends, the elderly are an enormous special market niche, which can make huge profits for companies [19]. This requires a different type of innovation, which is initiated not by a manufacturer (supply-driven), but based on the demand of older people (demand-driven), i.e. for market success the need of this category of consumers simply should be carefully revealed. Therefore, there are two unusual modern viewpoints which are vital for business. Firstly, successful ideas come from the outside of the organization, and secondly, monitoring of individual entrepreneurs and their intuitive initial guesses are the basis of market research that later would be usually successful.

Manufacturers even create unions and other civil society organizations (for example, the initiative «No Age») to coordinate their actions in adapting products to the needs of the older generation [20]. For example, when considering innovations in the field of health monitoring, some elderly people do not want to use technology that can reveal health problems they were not aware about previously. If the problem is potential and it has not bothered a consumer, precautions are perceived as meaningless. In this case, the producers of innovations must be proactive: innovation must be of benefit due to monitoring; the emphasis should be placed on maintaining a normal state of health, rather than revealing health problems.

Therefore, devices and their users should be aimed at solving the problem by harmonizing the interests, but during devices' development of already happening identification and clarification of issues to be solved by them focused. An interesting consequence of development of an innovation for the elderly is the fact that these innovations should be generally well accepted in all market segments due to their simplicity and functionality [21].

Another area of innovation for the elderly is development of devices and technologies which support the quality of life and well-being, but do not change consumer routines of pensioners [22]. The typical term for such a phenomenon is "assistive technologies". It includes information systems and devices that help to monitor, gather and analyze information about health status of the elderly. This is a very promising area of public development.

\section{Conclusion}

As a result of presented research we can argue that the innovation resistance is a multifactorial phenomenon. So the overcoming of innovation resistance is due to overcoming the factors of innovation resistance. It means that the best way of breaking through exogenous factors of resistance is development of market relations, high 
quality institutional environment, low transaction costs and the enhancement of self-expression values. Otherwise, the underdeveloped market relations can limit innovation activity in the business sector. Improvements in the competitive environment and market infrastructure are a prerequisite for the implementation of "bottom to top" innovations. It means that business and society can naturally be involved in the innovation process through the market mechanism.

Firms should implement effective marketing strategies in order to overcome endogenous factors of innovation resistance. It is important to realize that government can encourage consumers even the oldest ones to adopt innovations. This is only possible if government improves the institute of mutual social support for older people. The engagement of older people in education seems to be quite an effective mechanism to support their social activity in the context of innovation processes.

Thus, previous ideas could be formulated as the following. Older people and their routines are not so rigid and can be subjected to change. Innovation, albeit more slowly, is being included in the daily practice of the older generation. Not all areas of information and Internet technologies are in demand among the elderly, but if people see the sense and feel the satisfaction of their needs, they will learn and actively use these technologies. Sometimes they should be assisted in using these technologies. Sometimes the elderly should be provided with appropriate training. Nevertheless, the process of generating routines suitable for innovation use and innovative routines occur in this age group too. Manufacturers, realising how promising the market products for the elderly can be, do their best to meet the needs of old people by studying the features of this age group. Therefore, the most appropriate definition for the described process is "co-evolution" of the market agents in the niche of specific products intended for the older generation.

\section{Acknowledgment}

This work was performed by the authors in collaboration with Tomsk Polytechnic University within the project in «Development of a model of cross-regional cooperation in innovative activities», RFH project number № 16-0200492.

\section{References}

1. A.M. Dibrov, Procedia - Soc. and Behav. Sciences, 166, 92-96 (2015)

2. R.P. Bagozzi, Kyu-Hyun Lee, Adv. in Cons. Research, 26 (1), 218-25 (1999)

3. E.C. Hirschman, Adv. in Cons. Research, 14 (1), 57-60 (1987)

4. S. Ram, J. N. Sheth, J. of Cons. Marketing, 6 (2), 514 (1989)

5. R. Garcia, F. Bardhi, C. Friedrich, MIT Sloan Manag. Review, 48 (4), (2007)
6. F. Kunze, S. Boehm, H. Bruch, J. of Manag. Psychology, 28 (7/8), 741-760 (2013)

7. S.G. Winter, Yale Econ. Essays, 4 (1), 225-272 (1964)

8. P.S. Adler, B. Goldoftas, D.I. Levine, Org. Sc., 10 (1), 43-68 (1999)

9. M.C. Gilly, V.A. Zeithaml, J. of Cons. Research, 12 (3), 353-357 (1985).

10. M.C. Gilly, C.M. Wolfinbarger, H.J. Schau, J. of Cons. Affairs, 46 (1), 62-89 (2012)

11. T.A. Festervand, D.B. Meinert, S.J. Vitell, J. of Appl. Business, 10 (2), 13-22 (2011)

12. M.T. Braun, Computers in Human Behav., 29 (3), 673-680 (2013)

13. D. Gefen, E. Karahanna, D.W. Straub, MIS Quarterly, 27 (1), 51-90 (2003)

14. W. C. Phang, J. Sutanto, A. Kankanhalli, Y. Li, B. C. Y. Tan, H. H. Teo, IEEE Transactions of Engineering Manag., 53 (4), 555-569 (2006)

15. V. Venkatesh, F. D. Davis, Manag. Sc., 46 (2), 186204 (2000)

16. E. Frolova, M. Ryzhkova, International Conference on Economics and Management (ICEM 2015), 489492 (2015)

17. G. Punj, J. of Interactive Marketing, 25 (3), 134-144 (2011)

18. J. Zhou, P.-L. P. Rau, G. Salvendy, Int. J. of Human-Computer Interaction, 28, 799-826 (2012)

19. F. Kohlbacher, C. Herstatt, N. Levsen, Technovation, 39-40, 73-82 (2015)

20. A.J. Lassen, J. Bønnelycke, L. Otto, Technological Forecasting \& Social Change, 93, 10-18 (2015)

21. F. Kohlbacher, C.C. Hang, Ageing Int., 36 (1), 82101 (2011)

22. J. Teixeira, R. A. Suomi, Proceedings of the IADIS Int. Conf. ICT, Society and Human Beings. (2012) 